\title{
Judgment and Choice: Moral Judgment, Enjoyment and Meaningfulness in Interactive and Non-Interactive Narratives
}

\author{
Daniel M. Shafer ${ }^{1}$, Sophie Janicke ${ }^{2}$, Jonmichael Seibert ${ }^{3}$ \\ ${ }^{I}$ (Department of Film \& Digital Media/ Baylor University, USA) \\ ${ }_{2}^{2}$ (Department of Communication/ University of Arkansas, USA) \\ ${ }_{3}^{3}$ (Department of Communication and Information/ Florida State University, USA)
}

\begin{abstract}
This study extends Affective Disposition Theory (ADT) and the Integrated Theory of Enjoyment (ITE) to interactive television/film narratives. In the study, 168 participants were randomly assigned to experience one of two originally-produced films; one with interactive components, the other without. Participants in the interactive condition made choices for the protagonist throughout the films. Path analysis was used to examine hypotheses based on the ITE (using the recent perspective of enjoyment and meaningfulness as outcomes). Results indicate that the principles of ADT and ITE can be applied to interactive narrative forms. Suggestions for future research are offered.
\end{abstract}

Keywords - ADT, ITE, Meaningfulness, Enjoyment, Moral Choice, Interactivity

\section{INTRODUCTION}

Various perspectives that fall under the heading of entertainment theory have been developed to explain how the media we consume impacts our minds, attitudes, beliefs, and behaviors. Broadly, these perspectives help explain our selection and enjoyment of entertainment media. Three of these theories; excitation transfer theory (Zillmann, 1983), mood management theory (Zillmann, 1988), and affective disposition theory (ADT; Raney, 2003; 2006) were formulated with non-interactive media in mind (Vorderer et al., 2006). However, with the rise in popularity of interactive components embedded in television and film, as well as the stunning recent success of the video game industry, scholars have undertaken extensive exploration of interactivity as a key component of the entertainment experience (Grodal, 2000; Vorderer, 2000). One goal of the present study is to extend existing theories of enjoyment of entertainment fare, ADT in particular, to interactive media content.A recent trend in broadcast and cable television is the integration of interactive elements into the (traditionally passive) television viewer experience. Perhaps the most notable has been the Fox television show American Idol, which asks viewers to vote for their favorite singer and ultimately determine the winner of a lucrative recording contract. Other shows have followed suit such as The X Factor and So You Think You Can Dance (both on Fox), and NBCs The Voice, among others. The latest attempt at this innovation is the ABC offering Rising Star, which debuted in the summer season of 2014 (ABC Network, 2014). The show offers the first true attempt at a fan voting system that is implemented live in real time. This means that fans can directly decide a contestant's fate with no intermediary calculation process or data processing.

Other interactive innovations have been seen in the form of what are essentially interactive movies like the recent Playstation 4 release Until Dawn (Byles, 2015); and Quantic Dream's Heavy Rain, released in 2010 for the PS3 console (Quantic Dream, n.d.). These "games" are narrative-rich experiences which offer opportunities for action by the user. Many times, such action takes the form of choices the user makes for the main characters of the narrative. In the case of Heavy Rain, the game was both a commercial and critical success, making over \$2 million around the world, according to the developer (Quantic Dream, n.d.).

The emergence of more cinematic presentations in the video game world, as well as the noted recent attempts by the television industry to inject interactivity into the viewer experience provide an opportunity to revisit the application of traditional entertainment theories to interactive fare. While we acknowledge that video games are unique in their level of interactivity potential, we argue that forms of interactivity being integrated into traditionally passive media - such as audience voting and audience feedback - do in fact preserve the disposition formation and narrative experience processes that traditional entertainment theories explain so well.

One of the leading theoretical approaches that explain this narrative enjoyment process is the affective disposition theory (ADT). Several theories fall under the ADT umbrella such as the disposition theory of humor and mirth (Zillmann \& Cantor, 1976), the disposition theory of drama (Zillmann \& Bryant, 1975; Zillmann \& Cantor, 1976), the disposition theory of sports spectatorship (Raney, 2003), the moral sanction theory of delight and repugnance (Zillmann, 2000), and the integrated theory of crime drama enjoyment (Raney, 2002; 2005; 
Raney \& Bryant, 2002). The common argument of all ADT theories is that enjoyment is based on the moral judgments we make and the dispositions we form toward mediated characters. When thinking about interactivity in traditionally passive media, we argue that our choices in voting or audience feedback are inherently moral. For example, in the reality show Big Brother, voting for a houseguest to eat disgusting food; or for another houseguest to be safe from elimination is essentially a moral choice, or, at least, a disposition-based one. In traditional passive media, our moral mind is especially engaged when we have to make judgments about morally complex actions (e.g., embracing immoral actions to reach ostensibly noble goals). Researchers have recently put their attention to investigate how viewers negotiate their dispositions toward morally complex characters who engage in such morally complex actions (i.e., Krakowiak \& Oliver, 2012; Raney \& Janicke, 2013; Shafer, 2009; Shafer \& Raney, 2012).

Consequently, what drives our study is the question of how moral judgments inform the enjoyment process. We also inquire as to how interactivity may impact moral choice. Additionally, we are embracing the shift recent scholarship has suggested from focusing on enjoyment as the default outcome, toward a twopronged outcome formula that includes both hedonic (i.e., enjoyment) and eudaimonic (e.g., appreciation) responses (Oliver \& Bartsch, 2011; Oliver \& Raney, 2011). Lewis, Tamborini and Weber (2011) found greater appreciation for morally mixed narrative endings (where some moral intuitions are upheld and some are violated, cf. Tamborini, 2013) compared to purely positive "happy" endings, thus, lending support to investigate narrative experiences from a grand perspective (including enjoyment and meaningfulness) with the present study.

\subsection{Affective Disposition Theory}

Affective disposition theory explains the process that leads to enjoyment of a variety of mediated content (Raney, 2003; 2006; Zillmann \& Cantor, 1976). The theory argues that enjoyment is wrought through a continuous process of affective reactions to and moral judgments about the behavior of the protagonist and antagonist characters in the narrative. As long as we like and approve of a character's behavior, we hope for a good outcome and fear the negative.

By the same token, if we dislike and disapprove of a character's behavior, we hope for negative outcomes and fear the positive. When these two processes converge in one narrative in the form of hero vs. villain, as is common to many narratives, enjoyment is likely. We rejoice when those characters we like and empathize with triumph over those we dislike and feel counter-empathy toward. This process is described by Zillmann (2000), who proposed the moral sanction theory of delight and repugnance as an extension to his original theory. He asserted that we are "untiring moral monitors" (p. 54); continually rendering judgments about the behavior of characters throughout the mediated experience. These judgments can vary based on individual traits such as how empathic one may be, or based on attitudes held by the viewer such as their opinions on punitive punishment and vigilante justice, which has been shown to affect enjoyment in the Integrated Theory of Enjoyment (ITE, Raney, 2002; Raney \& Bryant, 2002; Raney, 2005).

As stimulus, Raney (2005) used a narrative where the protagonist killed the antagonist as punishment for the crime committed against him. Results showed that vigilantism predicted the judgments of deservedness and victim sympathy, which in turn predicted enjoyment (Raney, 2005). In a similar study, empathy, punitiveness, and vigilantism predicted victim sympathy, which in turn predicted enjoyment (Raney, 2002). Thus, for traditional dramas, research on the basis of ITE supports the relevance of these individual trait variables as predictors for moral judgments made about the behaviors of media characters.

\subsection{Morally Complex Characters}

ADT in its original formulation seems to assume a traditional hero/villain plot structure. However, the assumptions of ADT are challenged when characters do not follow the traditional formula. Raney $(2002 ; 2004)$ and others have investigated the disposition formation process when morally complex characters (Raney \& Janicke, 2013; e.g., antiheroes) take the protagonist role. These morally complex characters, such as Jack Bauer of 24, Dexter of Dexter, V of V for Vendetta, or The Bride in the Kill Bill films, often violate commonly held moral sanctions against murder, torture, or terrorism. But still, audiences flock to these and similar offerings. Empirical evidence suggests that viewers are able to disengage their moral standards that they typically rely on in order to continue enjoying narratives featuring morally complex characters (e.g., Janicke \& Raney, 2015; Krakowiak \& Tsay, 2011; Shafer \& Raney, 2012). That is, viewers find justifications that are oftentimes embedded within the narrative, in form of moral disengagement cues, to continue liking the main character. Liking the main character, of course, is necessary for any enjoyment experience according to ADT and the ITE. Shafer \& Raney (2012) applied the ITE to narratives featuring morally complex characters and found that in antihero narratives with no moral disengagement cues, viewers relied on their own empathy and attitudes about punitiveness and vigilantism to make moral judgments about characters. In narratives containing cues, individual empathy and attitudes faded in importance, and instead viewers made judgments in accordance with the cues presented. In both conditions, the narratives were similarly enjoyed. 
Based on the ITE-informed literature on narratives featuring morally weighty situations, we reaffirm that moral judgments are made in response to the actions of media characters (see Raney \& Janicke, 2013), and that judgments of how justified a certain action or outcome is for a character are influenced by the viewer's level of trait empathy and the attitudes the individual holds about social justice (i.e., punitiveness and vigilantism). To the extent that the viewer judges the outcome as justified, and their liked characters triumph over disliked characters, enjoyment will result. Consequently, when viewers of both interactive and non-interactive narrative make moral judgments or moral choices about the justification of a protagonist's actions, we expect that empathy, punitiveness, and vigilantism are predictors of such moral judgments (act/choice1 and act/choice2) $(H 1)$.Furthermore, we contend that increased interactivity will not change the processes predicted by ADT, but rather will simply enhance what already takes place by engaging the audience more deeply with the subject matter; essentially engaging them as participants in the story. When viewers become agents who are involved in and have impact upon the unfolding narrative, moral judgment is exchanged for moral choice.

\subsection{Moral Choice in Interactive Media}

In a study by Vorderer, Knobloch and Schramm (2001) participants were presented with a highly interactive, moderately interactive, or non-interactive TV movie. They found that for some participants, most notably those with higher cognitive capacity, the interactive forms of the TV movie were more enjoyable. But those with lower cognitive capacity preferred the non-interactive version. Cognitive capacity was based on several factors, but two contributors were age and education level (Vorderer et al., 2001). The study, however, did not investigate the processes leading to enjoyment in as much detail or with the specific focus of the present study.

As already noted, there is potential difficulty when applying traditional entertainment theories such as ADT to interactive media fare (Vorderer, et al., 2006). However, we argue that ADT and its extensions can certainly apply to a more interactive form of narrative; a narrative that is structured and scripted like a linear film or television show, but incorporates choices for viewers to make into the plot, effectively converting the passive viewer, briefly, into, essentially, the director of the story. As Vorderer and colleagues point out, ADT in the context of video games may not apply because moral judgments are (generally) being made about one's own actions, not the actions of a character under judgment. However, in the scenarios we are proposing, moral judgment and disposition formation is allowed to take place before presenting the viewer/participant with a choice. The viewer/participant becomes an agent of change in the narrative, but does not take on the role of the protagonist as they would in a video game. This allows us to introduce interactivity in the context of a story that can also be told with a traditional, linear approach; isolating the variable for study.

We propose, then, that the relationships dictated by the ITE (Raney \& Bryant, 2002) should hold true for an interactive short film just as they would for a traditional linear short film: Moral judgments of choice/act 1 as shown in the narrative will impact the moral judgments of choice/act $2(\mathrm{H} 2)$. Both moral judgments of the acts shown (or choices made), will predict the disposition towards the character (H3), which in turn will impact enjoyment and the assessment of meaningfulness of the film $(\mathrm{H} 4)$.

Additionally, we predict that the pattern of relationships between the variables will show little to no difference between the interactive and non-interactive conditions (H5). Instead, we expect the principles of ADT and, more specifically, the predictions of the integrated theory of crime drama enjoyment, to hold true for an interactive narrative just as for a non-interactive narrative.

\section{METHOD}

This study investigated ADT and the predictions of the integrated theory of crime drama enjoyment using a 2 condition (interactive vs. non-interactive) randomized experimental design. An original film, entitled Choose Your Own Apocalypse, was produced in two versions. The interactive version contained two distinct decision points where participants were required to make moral choices. The choice points were designed so that the choices were not necessarily right or wrong choices, morally speaking, for both decision points.

\subsection{Stimulus Material}

The film used for the stimulus material was written, produced, directed, edited, and largely acted by film and theater students at a major research university in the south-central United States. Using an original film offered several advantages over commercially-produced fare. First, there was no risk of the impact of previous exposure on the results. Second, having complete editorial power over the content of the films offered another measure of control that aided in the elimination of third-variable explanations. Third, since no famous or wellknown actors were used in the film, viewers were not influenced by any pre-conceived preferences, biases, or dispositions associated with liking or disliking a certain performer.

Choose Your Own Apocalypse is a post-apocalyptic action film. The film opens on two young women who are struggling to survive in a wasteland inhabited by savage enemies. When her friend Sarah is taken 
hostage by the cannibalistic Ravagers, Morgan must choose whether to negotiate for her release, or shoot at the Ravager in an attempt to free her (choice/act 1). In the process, Harper, acting as savior, rescues Morgan and another Ravager captive, Thomas. Leaving Sarah's body lifeless after a Ravager bullet finds her heart; the three survivors flee to Harper's nearby safe house. Outside, Harper tells them of a stash of ammunition that they will need to survive as they make a run from the Ravagers, who are advancing. They must choose who should leave the house to retrieve the box of ammo (choice/act 2). After a final confrontation with the Ravagers, the survivors escape toward the next safe house, with at least some shred of hope left for humanity.

\subsection{Participants and Procedure}

A sample of 165 college students was exposed to one of two randomly assigned conditions: an interactive film containing moral choices $(n=94)$; and a non-interactive film containing moral scenarios $(n=$ 71). The sample was $51 \%$ female and $49 \%$ male, with an average age of 20.1 years $(S D=1.83)$. After completing an IRB-approved consent form, participants viewed or interacted with the films in a small research laboratory with three research stations. Each station had a 32-inch 720p HD television set, which was connected to a personal desktop computer. The computer was used to present the stimulus material (by playing it from a DVD) and the online questionnaire. For the interactive film conditions, the DVD was programmed to present a new menu at each choice point. The menu consisted of the choices (e.g., shoot or negotiate). Once the choice was made, the film continued with the option chosen. For the non-interactive film conditions, the filmmakers were instructed to edit the films as they would if submitting the films to festivals or other forms of release. Therefore, participants viewed the director's cut versions of the films. Both films were approximately 20 minutes long.

\subsection{Measures}

Individual differences were measured prior to exposure to the film. Variables measured were limited to those found to be important in previous studies on ADT and the integrated theory of crime drama enjoyment (Raney, 2002; Raney \& Bryant, 2002). Empathy (Cronbach's $\alpha=.85)$, punitiveness $(\alpha=.85)$ and vigilantism ( $\alpha$ $=.94$ ) were measured as in Raney (2002 \& 2005), Raney and Bryant (2002), and Shafer and Raney (2012). One sample empathy question was: "When I'm upset at someone I usually try to put myself in their shoes for awhile"; rated from 1-7 on an agree-disagree Likert-type scale. Punitiveness and vigilantism were measured on the same type of scale, with sample items being "Punishment for a crime should involve physical pain" and " When I hear that a victim's family has gotten revenge on a criminal, I feel that justice is finally served", respectively.

Moral judgment in the interactive condition was assessed using a single item that referred to the choice the participant made: "To what extent did you feel that the choice you made was justified?" We asked participants to engage in meta-cognitive evaluation of their own choice (see Roberts \& Erdos, 1993). This evaluation was juxtaposed against the participants judgments about how justified the characters' choices were in the non-interactive condition. The item was changed from the interactive conditionand incorporated the scenario just shown. For example: "To what extent did you feel that the choice Morgan made to shoot the Ravager threatening Sarah was justified?"

Disposition toward the protagonist was assessed using two items: How good or evil do you think [the protagonist] is?" And "How much do you like [the protagonist]?" This measure of disposition assesses two key features of any disposition; a general moral judgment about the character, and a perception of how likable he or she is $(r=.67)$.

Enjoyment $(\alpha=.92)$ was also measured as in previous research (Raney, 2002; 2005, Raney \& Bryant, 2002, Shafer \& Raney, 2012). The nine-item scale included questions such as "How much did you enjoy watching the film?" and "How much would you like to experience the film again?" Items were measured on an 11-point continuum ranging from 0 (not at all) -10 (extremely).

Meaningfulness $(\alpha=.90)$ was measured using five items that asked participants to rate the film on five attributes which characterize eudaimonic responses to the content, as referred to by Oliver and Raney (2011) and Oliver and Bartsch (2011). The items were constructed based on the five terms mentioned by Oliver and Bartsch (2011) in their call for more empirical attention to the concept of appreciation or meaningfulness as an outcome of entertainment consumption. The items, shown in Table 1, were answered using the same $0-10$ response set as the enjoyment scale. A confirmatory factor analysis was conducted, and all items indicated high loadings on the latent variable meaningfulness. 
Table 1 Factor Loadings, SE and p-values for Meaningfulness Scale,

\begin{tabular}{lllll}
\hline Item & Factor Loading & $S E$ & $p$ value & $R^{2}$ \\
\hline How poignant was the film? & 0.62 & 0.12 & $<.001$ & 0.39 \\
How emotional was the film? & 0.73 & 0.15 & $<.001$ & 0.54 \\
How inspiring was the film? & 0.79 & 0.15 & $<.001$ & 0.62 \\
How moving was the film? & 0.94 & 0.13 & $<.001$ & 0.88 \\
How touching was the film? & 0.87 & 0.13 & $<.001$ & 0.76 \\
\hline
\end{tabular}

*Note: CFA $\chi^{2}=13.03, p=0.02$

\section{RESULTS}

\subsection{Hypothesis Testing}

The hypotheses were tested by specifying two path models, one for the interactive condition, and one for the non-interactive condition. Each model was tested with empathy, punitiveness, and vigilantism as exogenous variables leading to moral justification for/judgment of act/choice 1 and act/choice 2 . Act/choice 1 was set as a predictor of act/choice 2 and disposition. Act/choice 2 was set as a predictor of disposition only. Disposition, in turn, was specified as a predictor of both enjoyment and meaningfulness (see Fig. 1).

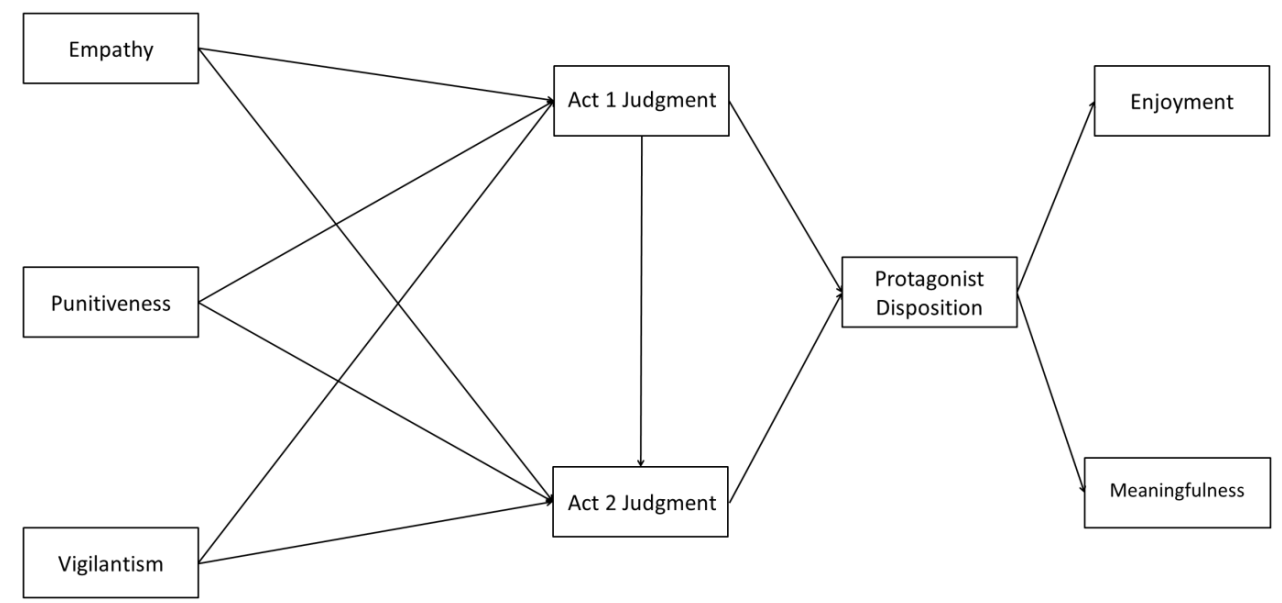

Figure 1. Hypothesized Model

The path models were analyzed using Lisrel 9.1. Fit indices for each model are listed in Table 2. CFI and SRMR are reported in lieu of the NNFI and AGFI. Hu and Bentler (1999) suggest SRMR and CFI are robust in cases where small sample size may be an issue.

Table 2Model Fit Indices

\begin{tabular}{lllllll}
\hline Model & Chi Square & $d f$ & $p$ value & RMSEA & SRMR & CFI \\
\hline Interactive & $\chi^{2}=67.23$ & 14 & 0.00 & 0.20 & 0.12 & 0.64 \\
Revised Interactive & $\chi^{2}=23.42$ & 13 & 0.04 & 0.09 & 0.08 & 0.94 \\
Non-interactive & $\chi^{2}=57.75$ & 14 & 0.00 & 0.21 & 0.14 & 0.55 \\
Revised Non-interactive & $\chi^{2}=16.39$ & 13 & 0.23 & 0.06 & 0.09 & 0.97 \\
\hline
\end{tabular}

As Table 2 shows, model fit was acceptable for the revised interactive and non-interactive models, although RMSEA failed to reach the desirable .05 level. Keeping in mind that finding a good-fitting model was a secondary goal to testing the hypotheses forwarded, we deemed the fit of the models acceptable for our purposes. Fig. 2 and Fig. 3 show the results of the path analyses for each condition.

Hypothesis 1 predicted that empathy, punitiveness and vigilantism would be predictors of moral justification judgments for both act/choice 1 and act/choice 2 . This hypothesis was only partially supported. Specifically, punitiveness emerged as a strong positive predictor of the justification of choice 1 in the interactive condition. The choice was whether to make Morgan shoot at the Ravager threatening her friend Sarah, or to make her attempt a negotiation for her release. Of the 94 participants in the condition, 41 chose to make Morgan shoot, and 53 chose for her to negotiate. A follow-up analysis of variance (ANOVA) showed that punitiveness 
was significantly higher among those participants who chose to make Morgan shoot at the Ravager $(M=4.46$, $S D=1.04)$ as compared to those who made her negotiate $(M=3.80, S D=1.14), F_{(1,92)}=8.31, p=.005, \eta^{2}=$ .083. Punitiveness was not a significant predictor in the non-interactive condition; however empathy was shown to impact how justified act 2 was in the non-interactive condition. Act 2 involved the three characters determining who should go into danger to retrieve a box of ammunition; the film shows Thomas being chosen via drawing of straws. Vigilantism did not emerge as a significant predictor of any of the choices or acts across conditions.

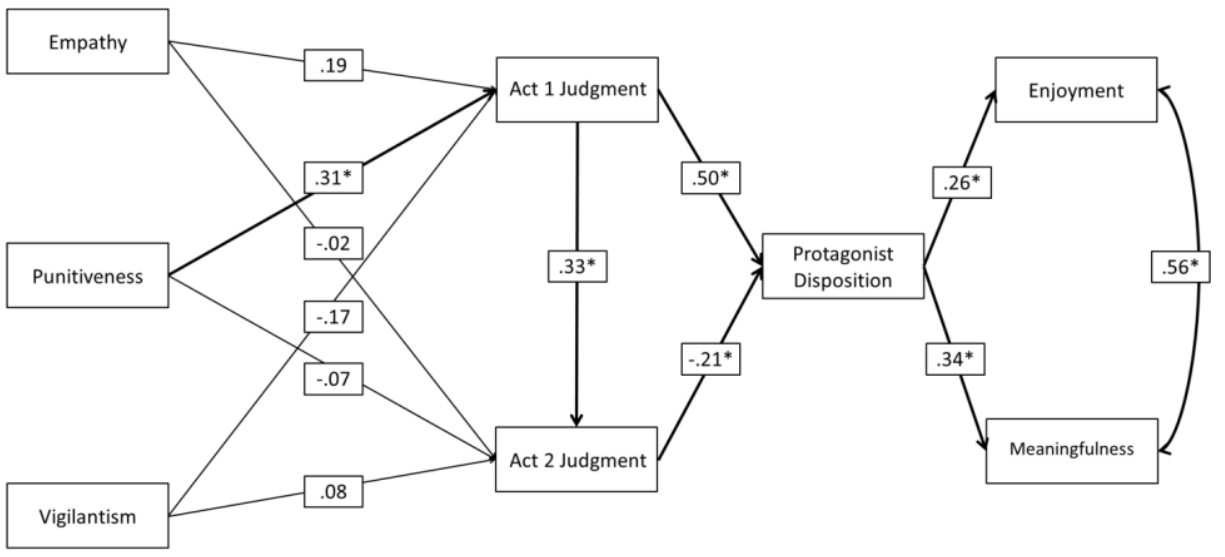

Figure 2. Final (Revised) Interactive Condition Model. Note. $* p<.05$

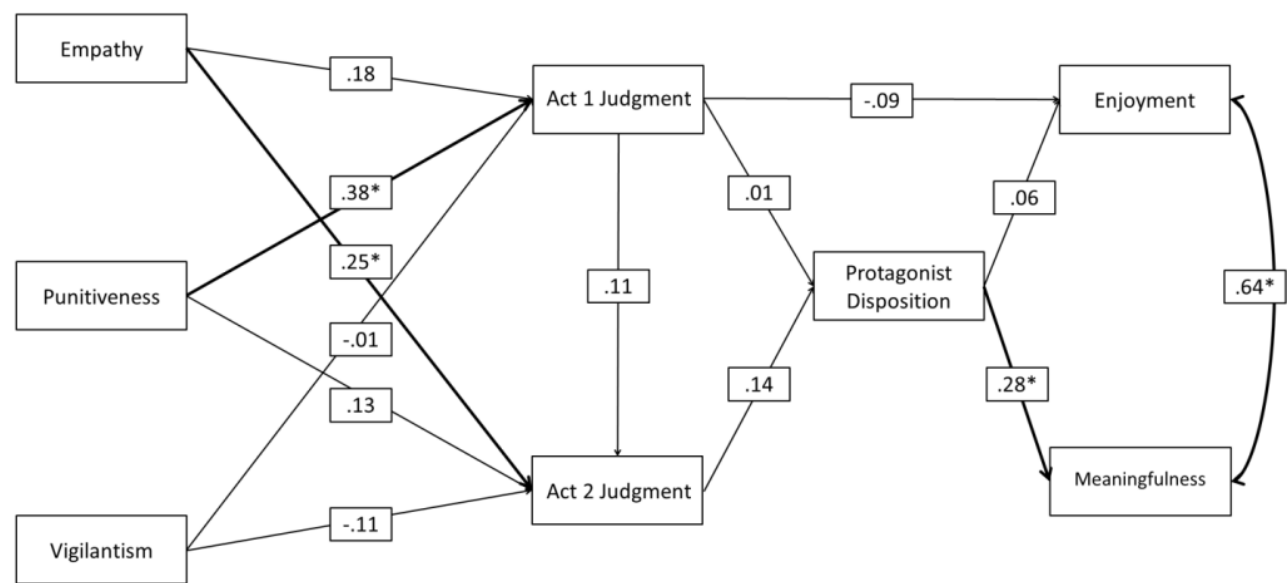

Figure 3. Final (Revised) Non-interactive Condition Model. Note. $* p<.05$

Hypothesis 2 predicted that justification of act/choice 1 would impact both the justification of act/choice 2 and disposition toward the protagonist. The path analyses showed partial support for $\mathrm{H} 2$. In the interactive condition, justification of choice 1 was significantly associated with justification of choice $2(r=$ .33). Act/choice 1 judgments also significantly and positively impacted disposition toward the protagonist (Morgan, $r=.50$ ).

In the non-interactive condition, there were no significant relationships between justification ratings of act 1 and act 2 , and act 1 did not go on to significantly predict disposition.

Hypothesis 3 predicted that justification of act/choice 2 would predict disposition. This hypothesis was supported for the interactive condition. Justification for act/choice 2 negatively impacted protagonist disposition. The negative effect $(r=-.21)$ was not as strong as the positive effect of act/choice $1(r=.50)$. H3 was unsupported in the non-interactive condition. Justification of act/choice 2 did not significantly impact disposition.

Hypothesis 4 predicted a significant effect of disposition on both enjoyment and meaningfulness. This hypothesis aligns with traditional ADT and acknowledges the latest scholarship that focuses on other outcomes besides simple hedonic pleasure. In the interactive condition, H4 was supported. Disposition toward Morgan positively impacted both enjoyment and meaningfulness. The more participants liked her and judged her positively, the more they found the film enjoyable and meaningful; keeping in mind that they themselves had a 
hand in her choices and circumstances (i.e. whether to shoot or negotiate with her enemies; whether or not she was sent into danger to retrieve supplies). In the non-interactive condition, disposition only significantly predicted meaningfulness. It seems participants did not derive their enjoyment from their liking and judgments of Morgan, but their feelings toward her did impact how meaningful they found the film to be.

In Hypotheses 5 we predicted no significant differences in the pattern of relationships of the variables between the interactive and non-interactive conditions. However, hypothesis 5 was not supported; there were some notable differences between the conditions. In the interactive condition, there was a clear and continuous route from punitiveness through the judgment of act 1 to disposition to enjoyment and meaningfulness. In the non-interactive condition, the traditional passive narrative, empathy and punitiveness did influence moral judgments, but those moral judgements did not impact disposition. Disposition did impact meaningfulness evaluations as predicted by the latest work on hedonic enjoyment and eudaimonic appreciation, but disposition did not influence enjoyment. The results would seem to indicate that interactivity; i.e. the ability to make choices for the characters, does align well with the predictions of the integrated theory of crime drama enjoyment and recent work on separating enjoyment from meaningfulness. The feature of interactivity seemed to engage participants more with the protagonist than the non-interactive version of the film. This heightened engagement allowed the participants' feelings for and judgment of the protagonist to impact both their enjoyment of the experience and how meaningful it was. We can assume that these observed relationships are, in fact, due to the interactivity feature of the narrative, because disposition, enjoyment, and meaningfulness were not significantly different between conditions (see Table 3).

Table 3Disposition, Enjoyment, and Meaningfulness Means Comparison

\begin{tabular}{cccccc}
\hline \multicolumn{2}{c}{ Disposition } & \multicolumn{2}{c}{ Enjoyment } & \multicolumn{2}{c}{ Meaningfulness } \\
\hline Interactive & Non-interactive & Interactive & Non-interactive & Interactive & Non-interactive \\
\hline$M=6.85$ & $M=6.73$ & $M=6.00$ & $M=5.55$ & $M=5.19$ & $M=4.99$ \\
$(S D=1.66)$ & $(S D=1.39)$ & $(S D=2.05)$ & $(S D=1.89)$ & $(S D=1.64)$ & $(S D=1.80)$ \\
\hline$F_{(1,163)}=0.27, p=.607$ & \multicolumn{2}{c}{$F_{(1,163)}=2.08, p=.151$} & $F_{(1,163)}=0.57, p=.451$ \\
\hline
\end{tabular}

\section{DISCUSSION}

This study investigated the predictions of ADT and the integrated theory of crime drama enjoyment in the context of interactive narratives. Interactivity was operationalized as the opportunity for participants to make choices for characters during exposure to a short originally-produced film. The study incorporates the latest thinking on enjoyment, which argues that hedonic pleasure is not the only possible outcome of experiencing entertainment. Appreciation or meaningfulness, a concept related to yet distinct from enjoyment, may also be a gratifying outcome (Oliver \& Bartsch, 2011; Oliver \& Raney, 2011). Indeed, the results show that enjoyment and meaningfulness were both significantly impacted by disposition toward the protagonist in the interactive model, and meaningfulness was impacted by disposition in the non-interactive model. These findings support the argument that the two experiences are not mutually exclusive; one can simultaneously experience hedonic enjoyment and meaningful appreciation in response to the same narrative.

\subsection{Individual Differences and Moral Judgment}

Perhaps the most notable finding is the difference in the pattern of effects between conditions. Individual attitudes about social justice seemed to have more salience in the non-interactive condition, in that both punitiveness and empathy influenced judgments of the moral choices/acts. In the interactive condition, only punitiveness impacted the judgment of choice/act 1. This does represent a consistent finding between conditions, that those who scored higher in punitiveness tended to judge the choice or act shown at decision point 1 as more justified than those lower in punitiveness. A post- hoc follow-up correlation analysis indicated that punitiveness was positively and significantly associated with choosing to shoot the Ravager in the narrative $(r=.29)$. These findings are consistent with ITE, which predicts and has empirically shown that individual attitudes about social justice influence moral judgments (Raney, 2002; 2005).

Furthermore, in the interactive condition, higher justification ratings for shooting the Ravager led to more positive dispositions toward the protagonist, Morgan. The justification rating for choice/act 2, however, was a negative predictor of disposition. This is likely due to the possibility that participants may not have perceived choice/act 2 as a moral one, per se. It seems that the choice for those in the interactive condition may have turned not on moral concerns, but rather on practical considerations. The protagonist, Morgan, had been shot and could barely walk. Harper, the character who saved the group from the Ravagers, had proven capable with weapons; but also professed knowledge of first aid, which Morgan needed. Thomas was presented in the narrative as timid and unassertive, and had no knowledge of first aid. Therefore it seems that the choice of which character should be sent into danger was largely a practical one. Thomas could not care for Morgan, and 
should therefore go; or, Harper should go because she had demonstrated competence in combat. Morgan was unable to help, and may have been seen by participants as a liability. She was portrayed as weak and in need of help, and this may have detracted from their positive judgment of her.

For those in the non-interactive condition, punitiveness predicted the moral justification of Act 1 and empathy predicted the moral justification of Act 2 . The decision of who to send to get the ammunition centered on the mechanic of drawing straws. Since the process of choosing someone to go into danger was apparently random, it is likely that participants were hoping for someone other than Morgan to be selected, considering her injury. Her situation seems to have evoked an empathic response, and when Harper is chosen, great relief may have followed.

This explanation highlights the fact that responses to narratives are not only subject to individual differences (i.e., user inputs), but are highly dependent upon narrative inputs or characteristics of the specific story (Raney \& Bryant, 2002). As shown in research on ITE, relationships between empathy, social justice attitudes and moral judgments do vary based on the elements presented in a narrative (i.e., severity of a crime; Raney, 2002; 2005). It also seems to be the case that, when comparing interactive and non-interactive versions of the film, the interactive version engaged participants with the story more than the non-interactive version by making them partially responsible for the outcome via their choices. This seems to have resulted in the metacognitive evaluations interactive condition participants made of their own choices feeding strongly into their dispositions toward the protagonist, for better or worse (see Figure 2).

\subsection{Disposition's Impact on Enjoyment and Meaningfulness}

Disposition positively impacted both enjoyment and meaningfulness in the interactive condition, and positively impacted meaningfulness in the non-interactive condition. As outlined earlier, interactivity, by turning viewers into directors, may inspire feelings of moral responsibility. This moral responsibility, especially in the case of the morally challenging choice of shooting versus negotiating for a person's life, should not only affect the disposition built towards the protagonist, but also should make the experience meaningful. A related study on two different narratives found that participants exposed to a morally complex narrative experienced greater appreciation (i.e., meaningfulness) than participants exposed to a morally clear hero narrative (Janicke \& Shafer, 2014).

These results imply that narratives which are poignant, moving, touching, and inspiring may, based on our ability to interact with morally challenging situations, affect how empathetic we are when making moral choices in real life. Or, they may inspire us to be more conscious of our moral actions in real life. In fact, Grizzard and his colleagues (2014) found that making moral choices in video games, specifically immoral ones, can increase a player's moral sensitivity, potentially leading to more prosociality in real life. Moral rumination may be a valuable practice, and morally challenging narratives can inspire it. Janicke \& Shafer (2014) found that participants judged antihero narratives significantly more thought provoking than hero narratives. In sum, both interactive and traditional (non-interactive) narratives may be specifically meaningful for a viewer when they are morally engaging. Adding interactivity seems to also heighten the effect of disposition on enjoyment. This shows that taking moral responsibility for what characters do can be both meaningful and enjoyable, and that the process of enjoyment described by ADT and its related theories can be applied to interactive narratives.

\subsection{Limitations}

The study is the first that investigates how moral choices in interactive narrative entertainment impact the enjoyment process based on the predictions of ADT. One notable limitation of the study is that the sample size in each path analysis condition is small. A general rule of thumb for adequate sample size is that there should be at least 5 times the number of paths to be specified (SAS Institute, Inc., 1990). Our model tested 11 paths originally, meaning the minimum sample size should have been 55 for each model tested. This was not the case; sample sizes for the models ranged from 38 - 47. This does introduce some uncertainty as to the stability of our results. As a partial remedy, we have reported fit indices that are robust to small sample size in path analysis (Hu \& Bentler, 1999). These fit indices indicate that, despite not reaching a desired sample size threshold, our results can be taken with some confidence due to acceptable final model fit.

\section{CONCLUSION}

This study has shown that ADT and the integrated theory of crime drama enjoyment can be extended to explain enjoyment and appreciation of certain narrative forms that incorporate limited amounts of interactivity. More research is needed to determine if the principles of ADT hold true in a fully interactive mediated environment such as a video game. Future work should investigate how certain variables such as avatar identification operate on disposition, moral judgment, enjoyment and appreciation of video game narratives. Additionally, we have suggested that increased moral engagement may have resulted from making moral choices in the narrative. Empirical evidence is needed to verify our suggestions. One potentially viable measure 
of engagement could be galvanic skin response measured during morally-charged narratives, although many other variables such as plot and level of action would have to be controlled; another possible measure may be functional magnetic resonance imaging (fMRI) or some other type of neurological reading taken during exposure, as has been done in several studies related to interactive media (e.g., Mathiak \& Weber, 2006; Weber, Ritterfeld \& Mathiak, 2006).

Also, to extend this scholarship, the inclusion of moral foundations (Haidt, 2008) as an additional predictor of moral choices would be useful. As seen in our models, only two of the trait variables significantly predicted moral judgments. The inclusion of a variable assessing an individual's moral makeup, as measured with MFT, may enhance the variance explained in interactive and non-interactive entertainment fare.

To conclude, this study further demonstrates the utility and adaptability of Zillmann's affective disposition theory, yet highlights the continued importance of challenging, refining, and extending its propositions. ADT continues to be one of the most comprehensive theories on how we experience many types of entertainment, and as such, warrants continued investigation and application as the media landscape shifts and develops.

\section{REFERENCES}

[1] D. Zillmann, "Transfer of excitation in emotional behavior," in Social Psychophysiology: A Sourcebook, J. T. Cacioppo and R. E. Petty, Eds. New York: Guilford Press, 1983, pp. 215-240.

[2] D. Zillmann, "Mood Management through Communication Choices," American Behavioral Scientist, vol. 31, no. 3, pp. 327-340, Jan. 1988.

[3] A. A. Raney, "Disposition-based theories of enjoyment," in Communication and emotion: Essays in honor of Dolf Zillmann, J. Bryant, J. Cantor, and Roskos-Ewoldsen, Eds. Mahwah, N.J.: Lawrence Erlbaum Associates, 2003, pp. 61-84.

[4] A. A. Raney, "The psychology of disposition-based theories of media enjoyment," in Psychology of Entertainment, J. Bryant and P. Vorderer, Eds. Mahwah, N.J.: Lawrence Erlbaum Associates, 2006, pp. 137-150.

[5] P. Vorderer, J. Bryant, Pieper, K.M., and R. Weber, "Playing video games as entertainment," in Psychology of Entertainment, J. Bryant and P. Vorderer, Eds. Mahwah, N.J.: Lawrence Erlbaum Associates, 2006, pp. 1-7.

[6] T. Grodal, Video games and the pleasures of control. In: Zillmann D, Vorderer P, editors. Media entertainment: the psychology of its appeal. Mahwah, NJ: Lawrence Erlbaum Associates; 2000. p. 197214.

[7] P. Vorderer, "Interactive entertainment and beyond," in Media entertainment: the psychology of its appeal, D. Zillmann and P. Vorderer, Eds. Mahwah, NJ: Lawrence Erlbaum Associates, 2000, pp. 21-36.

[8] ABC Network, Rising Star. Retrieved 6/20/2014 from http://abc.go.com/shows/rising-star, 2014.

[9] W. Byles, Until Dawn ${ }^{T M}$. Supermassive Games, 2015.

[10] Quantic Dream, Heavy Rain. Retrieved 6/20/2014 from http://www.quanticdream.com/en/game/heavyrain, n.d.

[11] D. Zillmann and J. R. Cantor, "A disposition theory of humour and mirth.," in Humour and Laughter: Theory, Research and Applications, A. J. Chapman and Foot, H. C., Eds. London: John Wiley \& Sons, 1976, pp. 93-115.

[12] D. Zillmann and J. Bryant, "Viewer's moral sanction of retribution in the appreciation on dramatic presentations," Journal of Experimental Social Psychology, vol. 11, pp. 572-582, 1975.

[13] D. Zillmann, "Basal morality in drama appreciation," in Moving Images, Culture and the Mind, I. Bondebjerg, Ed. Luton, UK: University of Luton Press, 2000, pp. 53-63.

[14] A. A. Raney, "Moral Judgment as a Predictor of Enjoyment of Crime Drama," Media Psychology, vol. 4, no. 4, pp. 305-322, 2002.

[15] A. A. Raney, "Punishing Media Criminals and Moral Judgment: The Impact on Enjoyment," Media Psychology, vol. 7, no. 2, pp. 145-163, 2005.

[16] A. A. Raney and J. Bryant, "Moral Judgment and Crime Drama: An Integrated Theory of Enjoyment," Journal of Communication, vol. 52, no. 2, pp. 402-415, Jun. 2002.

[17] K. M. Krakowiak and M. B. Oliver, "When good characters do bad things: Examining the effect of moral ambiguity on enjoyment," Journal of Communication, vol. 62, no. 1, pp. 117-135, 2012.

[18] A. A. Raney and Janicke, Sophie, "How we enjoy and why we seek out morally complex characters in media entertainment," in Media and the Moral Mind, R. C. Tamborini, Ed. London: Routledge, 2013, pp. $152-169$.

[19] D. M. Shafer, "Moral disengagement toward protagonists for the enjoyment of fictional narratives," presented at the annual convention of the International Communication Association, Chicago, IL, 2009. 
[20] D. M. Shafer and A. A. Raney, "Exploring how we enjoy antihero narratives," Journal of Communication, vol. 62, no. 6, pp. 1028-1046, 2012.

[21] M. B. Oliver and A. Bartsch, "Appreciation of Entertainment: The Importance of Meaningfulness via Virtue and Wisdom," Journal of Media Psychology: Theories, Methods, and Applications, vol. 23, no. 1, pp. 29-33, Jan. 2011.

[22] M. B. Oliver and A. A. Raney, "Entertainment as Pleasurable and Meaningful: Identifying Hedonic and Eudaimonic Motivations for Entertainment Consumption," Journal of Communication, vol. 61, no. 5, pp. 984-1004, Oct. 2011.

[23] R. J. Lewis, R. Tamborini, and R. Weber, "Testing a dual-process model of media enjoyment and appreciation," presented at the annual convention of the National Communication Association, New Orleans, LA, Nov. 2011.

[24] R. C. Tamborini, "A model of intuitive morality and exemplars," in Media and the Moral Mind, R. C. Tamborini, Ed. London: Routledge, 2013, pp. 43-74.

[25] A. A. Raney, "Expanding Disposition Theory: Reconsidering Character Liking, Moral Evaluations, and Enjoyment," Communication Theory, vol. 14, no. 4, pp. 348-369, Nov. 2004.

[26] S. H. Janicke and A. A. Raney, "Exploring the role of identification and moral disengagement in the enjoyment of an antihero television series," Communications, vol. 40, no. 4, Jan. 2015.

[27] K. M. Krakowiak and M. Tsay, "The role of moral disengagement in the enjoyment of real and fictional characters," International Journal of Arts and Technology, vol. 4, no. 1, p. 90, 2011.

[28] P. Vorderer, S. Knobloch, and H. Schramm, "Does entertainment suffer from interactivity? The impact of watching an interactive TV movie on viewers' experience of entertainment," Media Psychology, vol. 3, no. 4, pp. 343-363, 2001.

[29] M. J. Roberts and G. Erdos, "Strategy Selection and Metacognition," Educational Psychology, vol. 13, no. 3-4, pp. 259-266, Jan. 1993.

[30] L. Hu and P. M. Bentler, "Cutoff criteria for fit indexes in covariance structure analysis: Conventional criteria versus new alternatives," Structural Equation Modeling: A Multidisciplinary Journal, vol. 6, no. 1, pp. 1-55, Jan. 1999.

[31] S. H. Janicke and D. M. Shafer, "Applying the narrative enjoyment and appreciation rationale (NEAR) to antihero narratives," presented at the annual convention of the National Communication Association, Chicago, IL, 2014.

[32] M. Grizzard, R. Tamborini, R. J. Lewis, L. Wang, and S. Prabhu, "Being Bad in a Video Game Can Make Us Morally Sensitive," Cyberpsychology, Behavior, and Social Networking, vol. 17, no. 8, pp. 499-504, Aug. 2014.

[33] SAS Institute, Inc. SAS User's Guide: Statistics. Cary, NC: SAS Institute, Inc., 1990.

[34] K. Mathiak and R. Weber, "Toward brain correlates of natural behavior: fMRI during violent video games," Human Brain Mapping, vol. 27, no. 12, pp. 948-956, Dec. 2006.

[35] R. Weber, U. Ritterfeld, and K. Mathiak, "Does playing violent video games induce aggression? Empirical evidence of a functional magnetic resonance imaging study," Media Psychology, vol. 8, no. 1, pp. 39-60, Feb. 2006.

[36] J. Haidt, "Morality," Perspectives on Psychological Science, vol. 3, no. 1, pp. 65-72, Jan. 2008. 